\title{
Assessment and comparison between effectiveness of techniques of improving lactation among postnatal mothers of new born babies
}

\author{
Anita Asrani', Achamma Varghese ${ }^{2}$, Balkishan Sharma ${ }^{3}$, Anil Kumar Jain ${ }^{4}$ \\ ${ }^{1}$ Sister Tutor, Department of Pediatric Nursing, Government College of Nursing, Ujjain Madhya Pradesh, India \\ ${ }^{2}$ Professor and Principal, Index College of Nursing, Indore (M. P.), India, ${ }^{3}$ Associate Professor (Biostatistics), \\ Department of Community Medicine, Sri Aurobindo Medical College and P. G. Institute, Indore (M. P.), India, ${ }^{4}$ Director, \\ Devi Ahiliya Vaikalpik Chikitsa Avam Shodh Sansthan, Indore (M. P.) India
}

Background: Breast milk is a combination of food and ailor made medicine to meet the requirements of the new born, is extremely easy to digest and is therefore the perfect first food for the new born. Aims and Objectives: Authors evaluated 60 postnatal mothers of new born babies to determine the effectiveness of back massage as compared to cumin seeds laddo techniques on improving lactation. Materials and Methods: A quasi experimental study designed among sixty postnatal mothers to observe the effectiveness of methods of improving lactation randomly dived into two groups. Subjects of group 1 received back massage while cumin seed laddoo provided to subjects of group 2 . The ethical clearance was obtained. Data recorded at baseline (pretest) and for three successive days, 1, 2 and 3 post administration (post-test). Results: $83.3 \%$ of the post natal mothers of group 1 $\left(n_{1}=30\right)$ and $86.7 \%$ of group $2\left(n_{2}=30\right)$ observed without any previous problem in breast feeding. The appearance of stool found to be associated significantly post administration on day $2(p<0.003)$ and day $3(p<0.006)$ with used techniques. On day $3,63.3 \%$ noticed with good category received back massage against $40.0 \%$ administered cumin seed laddo. Mean birth weight of baby $(2681.33 \pm 260.89 \mathrm{gram})$ at post-test of group 1 was higher than group 2 (2607.00 \pm 402.19 gram). Differences in mean number of nappies wetted, number of feed and time taken by the baby between groups on days 2 and 3 were highly significant $(p<0.001)$. Average total post-test scoring were statistically significant on day $3(p<0.05)$. However, back massage was more effective than cumin seed laddo. Conclusion: This study supports the view of improvement in lactation among post natal mother incorporated to good health of new born by administering back massage. In the Indian context, there are many studies carried out on improvement in lactation among post natal mothers but none of the study demonstrated comparison between two lactation techniques.

Key Words: Effectiveness, Lactation, Back massage, Cumin seed laddoo, Breast feeding
http://nepjol.info/index.php/AJMS DOI: 10.3126/ajms.v9i1.18625 E-ISSN: 2091-0576 P-ISSN: 2467-9100

\section{INTRODUCTION}

Lactation among postnatal mothers is beneficial to mother's health as well as provides specific nourishments, growth and development to the baby. Breast milk is nature's most precious gift to the new born. Exclusive breast feeding for initial six months is an important tool to reduce infant mortality rate in developing countries. It has been shown that breast milk decreases the rate of common infections even in preterm babies. ${ }^{1}$ Studies conducted in both developing and industrialized countries have shown a clear relationship between breast-feeding and a decreased incidence of infections in full-term infants. $^{2-5}$ 
Breast milk is the nutritious diet for newborns Indeed, of the 6.9 million under five children who were reported dead globally in 2011, an estimated 1 million lives could have been saved by simple and accessible practices such as exclusive breastfeeding. ${ }^{3}$ Scientific research studies conducted during the last three decades have clearly proved that breastfeeding provides the most suitable nutrition for an infant. The back massage was more effective therapy for relaxing the mothers surely beneficial and helpful in production of more breast milk. Use of breast milk substitutes increases the risk of morbidity and mortality among infants.

Iron deficiency is thought to be the most common nutrient deficiency among pregnant women (WHO 1992) and various study reported the effect of selected diet containing calcium and iron on improving lactation in postnatal mother. ${ }^{6}$ Cumin seeds which is a high sources of iron (100gm of cumin seed $=11.7 \mathrm{mg}$ of iron) is good for lactating mother as they are more in need of iron than others. However in India, breastfeeding is inadequately practiced due to prevailing misconceptions and cultural taboos.

Motivation for breast feeding, social support, nursing frequency and good breast feeding experience are other factors have positive impact on lactation. ${ }^{7}$ Breast feeding is practiced by health care professionals for benefitting the mother and her child in all health aspects. Few mothers were unable to produce breast milk; it affected the health of the child. ${ }^{8}$

Breastfeeding is considered as one of the most natural and intimate of all human interactions. Human milk has no substitute and breast is nature's apparatus for feeding babies. There are so many factors influence on breast milk secretions such as anemia, toxemia, any chronic diseases, early primigravida, and failure of mother to suckle her child regularly, depression (or) anxiety, premature baby too weak to such, and painful breast lesion all may influence on breast milk. ${ }^{9}$

Breast milk remains the ideal nutritional source for the baby through the first year of life. Only $24.5 \%$ of new mothers initiate breast feeding in $1^{\text {st }}$ hour after birth. Only $46.4 \%$ exclusively breast feed up to 6 months published by National Family Health Survey-3 (NFHS-3) in 2006 and the data indicated India is well below the healthy people 2010 goals. ${ }^{10}$ There is widespread need of identifying practical issues in implementing early breast feeding and sustaining it. Simple and less expensive methods applicable to vast majority of the population should be an answer. For many years China has used Acupressure to increase milk production. ${ }^{11}$ Implementation of strategies to promote longer breastfeeding duration and exclusivity are needed to reduce health care costs and improve population health ${ }^{12}$.

Professional health care organizations universally and actively encourage the support necessary to promote successful establishment and maintenance of breastfeeding. These organizations include various medical, nursing and other elite societies. There is a need for dissemination of information and education regarding optimal breast feeding practices and for protecting and promoting healthy practices. ${ }^{13} \mathrm{It}$ is an integral part of the reproductive process and its effect on child spacing, family health, family and national economy and food production is well recognized. ${ }^{14}$ These beneficial properties of breast milk though known to mankind for centuries, have been established scientifically during the last few decades. ${ }^{15}$

In the Indian context, there are many studies carried out on improvement in lactation among post natal mothers but none of the study demonstrated comparison between lactation techniques. In the similar context, the main objective of the study was to identify the therapy which is beneficial in improving lactation, technically, helpful in producing enough of breast milk among post natal mothers.

The authors hypothesized that back massage among post natal mothers may be a better method enhancing the production of breast milk than method of providing cummin seed laddo was the goal of research. The experience in conduction of the present research was exotic and remarkably new. However, the mother may gain knowledge about therapy of back massage through this research was more effective in improving lactation which is responsible for growth and overall development to the baby. Henceforth, the authors aimed to utilize the breast milk improving techniques to demonstrate the advantages and the significance of the technique.

\section{Purpose}

The present study showed a comparison between the effectiveness of methods of back massage and cumin seeds laddo on improvement in lactation among postnatal mothers of new born babies. The findings of the study were analyzed and discussed.

\section{MATERIALS AND METHODS}

\section{Background and study design}

A quasi experimental study designed and carried out at Sri Aurobindo College of Nursing, Indore (M. P.), India among post natal mothers.

\section{Participants and data collection method}

Sixty post natal mothers purposively selected for the study during April 2015 to May 2015 within 45 days. Ethical 
approval obtained from the institution and prior informed consent from the post natal mothers obtained for the publication of the clinical details. Postnatal mothers whose breast feeding score was 0-3 scored on $2^{\text {nd }}$ day on Modified Breast Feeding Assessment Scale, not able to satisfy their babies with enough milk, has normal term baby appropriate for gestational age while considered after 24 hours of the history of no milk to feed her baby and willing to breast feed her baby were included and those with medical problems, newborn with prematurity, poor sucking reflex and congenital abnormalities were excluded from the study.

Sixty subjects divided into two equal halves randomly. The main study tool was a modified breast feeding assessment scale and after explaining the purpose of the study the scale and structured interview was carried out in groups to assess the pre-test (baseline). The back massage was given to subjects of group 1 while cumin seed laddoo was provided to subjects of group 2. After administration on days 1, 2 and 3, the data were recorded again stored as post-test. Each variable recorded for three times in a day at baseline and post administration stages for next three successive days and an average value for all selected parameters utilized for further statistical analysis.

\section{Statistical analysis}

Descriptive and inferential statistics were used. Unpaired/ paired t-test was used to demonstrate the significance of mean differences between/within group 1 and group 2 at pre-test and post-test from days 1 to 3. Pearson's ChiSquare test used to analyze the association of appearance of stools and duration of sleep of new born baby in 24 hours with method of improving lactation before and after administration on days (1,2 and 3$)$. The probability value $\mathrm{p} \leq 0.05$ was considered statistically significant.

\section{RESULTS}

A maximum of 60 postnatal mothers of new born babies responded to study. The type of delivery in both the

\begin{tabular}{|c|c|c|c|c|}
\hline \multirow[t]{2}{*}{ Parameter } & \multicolumn{2}{|c|}{ Group 1} & \multicolumn{2}{|c|}{ Group 2} \\
\hline & $\begin{array}{l}\text { Frequency } \\
\left(\mathrm{n}_{1}=30\right)\end{array}$ & Percent & $\begin{array}{c}\text { Frequency } \\
\left(\mathrm{n}_{2}=30\right)\end{array}$ & Percent \\
\hline \multicolumn{5}{|l|}{ Age (year) } \\
\hline $18-23$ & 17 & 56.7 & 17 & 56.7 \\
\hline $24-29$ & 9 & 30.0 & 11 & 36.7 \\
\hline $30-35$ & 4 & 13.3 & 2 & 6.7 \\
\hline \multicolumn{5}{|c|}{ Any previous problem in breast feeding } \\
\hline Yes & 5 & 16.7 & 4 & 13.3 \\
\hline No & 25 & 83.3 & 26 & 86.7 \\
\hline
\end{tabular}

groups among selected post natal mothers was vaginal and $83.3 \%$ of the post natal mothers in group 1 and $86.7 \%$ of group 2 observed without any previous problem in breast feeding. $93.3 \%$ of group 1 used breast milk to feed the baby at pretest was higher in proportion as compared to $76.7 \%$ of group 2 .

Table 1 showed that the post natal mothers in the groups, 1 and $2(56.7 \%)$ observed more frequently in the age group of 18-23 years. The age group of 24-29 years consisted of $30.0 \%$ post natal mothers belonged to group 1 but $36.7 \%$ observed in group 2 . Few $(13.3 \%$ and $6.7 \%)$ post natal mothers of group 1 and group 2 identified in the age group of $30-35$ years.

Table 2 reports the distribution and association of appearance of stool of new born baby with respect to used techniques. Appearance of stool in 24 hours had a strongly significant relationship with used techniques on days 2 and 3 post administration. But, no significant differences noted between two techniques before administration at baseline.

At pretest stage, the appearance of stool of $70.0 \%$ new born babies in 24 hours of group 1 was black was lower than $83.3 \%$ of group 2 . The postnatal mothers of group 1 experienced the black appearance of stool of $100.0 \%$ new born on day 1 but on days 2 and 3 and found to be changed and had more frequently yellow in $96.7 \%$ babies. Appearance of stool of $100.0 \%$ new born babies of group 2 at posttest stage on day 1 was black but on days 2 and 3 was changed and noticed yellow in $70.0 \%$ babies. Statistically, these differences in appearance of stool of new born baby in 24 hours found to be associated highly significantly post administration on day $2(p<0.003)$ and day $3(p<0.006)$ with used techniques but no significant association before $(p>0.05)$ administration at baseline. These differences in appearance of stool reflected a better improvement in lactation among postnatal mothers of group 1 than group 2 .

Table 3 reports the relationship of duration of sleep of new born baby with used techniques of improving lactation among post natal mothers. At pretest stage, the duration of sleep of new born in 24 hours was found to be approximately similar in groups. After administration there was a successive improvement in duration of sleep in both the groups. The duration of sleep of 18-20 hours was noted in $53.3 \%$ newborns on day 2 and was in $76.7 \%$ on day 3 in group 1 while in group 2 this was observed in $53.3 \%$ newborns on day 2 was same but was more, in $83.3 \%$ on day 3 .

The duration of sleep of 20-22 hours was noted in 3.3\% newborns on day 2 and was in $20.0 \%$ on day 3 in group 1 


\begin{tabular}{|c|c|c|c|c|c|}
\hline \multirow[t]{2}{*}{ Sampling stage } & \multirow[t]{2}{*}{ Variables } & \multicolumn{2}{|c|}{ Method of improving lactation } & \multirow[t]{2}{*}{ Total (\%) } & \multirow{2}{*}{$\begin{array}{c}\text { p-value } \\
\text { LOS }\end{array}$} \\
\hline & & Back massage (\%) & Cumin seed laddo (\%) & & \\
\hline \multirow[t]{2}{*}{ Before administration } & Black & $21(70.0)$ & $25(83.3)$ & $46(76.7)$ & \multirow[t]{2}{*}{$\begin{array}{l}\chi_{1}^{2}=1.49 \\
p>0.05^{\otimes}\end{array}$} \\
\hline & No stool & $9(30.0)$ & $5(16.7)$ & $14(23.3)$ & \\
\hline \multicolumn{6}{|l|}{ After administration } \\
\hline Day 1 & Black & $30(100.0)$ & $30(100.0)$ & $60(100.0)$ & \multirow{3}{*}{$\begin{array}{c}\text { NA } \\
\chi_{1}^{2}=9.02 \\
p<0.003^{\#}\end{array}$} \\
\hline \multirow[t]{2}{*}{ Day 2} & Black & $1(3.3)$ & $10(33.3)$ & $11(18.3)$ & \\
\hline & Yellow & $29(96.7)$ & $20(66.7)$ & 49 (81.7) & \\
\hline \multirow[t]{2}{*}{ Day 3} & Black & $1(3.3)$ & $9(30.0)$ & $10(16.7)$ & \multirow[t]{2}{*}{$\begin{array}{c}\chi_{1}^{2}=7.68 \\
p<0.006^{\#}\end{array}$} \\
\hline & Yellow & $29(96.7)$ & $21(70.0)$ & $50(83.3)$ & \\
\hline
\end{tabular}

"The association is highly significant at the 0.006 and 0.003 levels of significance. ${ }^{\otimes}$ The association isn't (Insignificant) significant at the 0.05 level of significance. [LOS-Level of Significance; NA-Not Applicable]

Table 3: Association of duration of sleep with method of improving lactation before and after administration on day 1 , day 2 and day 3 in groups

\begin{tabular}{|c|c|c|c|c|c|}
\hline \multirow[t]{2}{*}{ Sampling stage } & \multirow[t]{2}{*}{ Variables (hours) } & \multicolumn{2}{|c|}{ Method of improving lactation } & \multirow{2}{*}{$\begin{array}{l}\text { Total; } \\
\text { f (\%) }\end{array}$} & \multirow{2}{*}{$\begin{array}{c}p \text {-value } \\
\text { LOS }\end{array}$} \\
\hline & & Back massage; $f(\%)$ & Cumin seed laddo; $f(\%)$ & & \\
\hline \multirow[t]{4}{*}{ Before administration } & $20-22$ & $14(46.7)$ & $14(46.7)$ & $28(46.7)$ & $\begin{array}{l}\chi_{1}^{2}=1.22 \\
p>0.05^{\otimes}\end{array}$ \\
\hline & $18-20$ & $5(16.7)$ & $5(16.7)$ & $10(16.7)$ & \\
\hline & $16-18$ & $10(33.3)$ & $8(26.7)$ & $18(30.0)$ & \\
\hline & $\leq 16$ & $1(3.3)$ & $3(10.0)$ & $4(6.7)$ & \\
\hline \multicolumn{6}{|l|}{ After administration } \\
\hline \multirow[t]{4}{*}{ Day 1} & $20-22$ & $3(10.0)$ & $2(6.7)$ & $5(8.3)$ & $\begin{array}{l}\chi_{1}^{2}=1.99 \\
p>0.05^{\otimes}\end{array}$ \\
\hline & $18-20$ & $2(6.7)$ & $5(16.7)$ & $7(11.7)$ & \\
\hline & $16-18$ & $14(46.7)$ & $15(50.0)$ & $29(48.3)$ & \\
\hline & $\leq 16$ & $11(36.7)$ & $8(26.7)$ & $19(31.7)$ & \\
\hline \multirow[t]{4}{*}{ Day 2} & $20-22$ & $1(3.3)$ & $0(0.0)$ & $1(1.7)$ & $\begin{array}{l}\chi_{1}^{2}=1.55 \\
p>0.05^{\otimes}\end{array}$ \\
\hline & $18-20$ & $16(53.3)$ & $16(53.3)$ & $32(53.3)$ & \\
\hline & $16-18$ & $10(33.3)$ & $9(30.0)$ & 19 (31.7) & \\
\hline & $\leq 16$ & $3(10.0)$ & $5(16.7)$ & $8(13.3)$ & \\
\hline \multirow[t]{3}{*}{ Day 3} & $20-22$ & $6(20.0)$ & $0(0.0)$ & $6(10.0)$ & $\begin{array}{l}\chi_{1}^{2}=8.75 \\
p<0.02^{*}\end{array}$ \\
\hline & $18-20$ & $23(76.7)$ & $25(83.3)$ & $48(80.0)$ & \\
\hline & $16-18$ & $1(3.3)$ & $5(16.7)$ & $6(10.0)$ & \\
\hline
\end{tabular}

"The association is highly significant at the 0.02 level of significance. ${ }^{\otimes}$ The association isn't (Insignificant) significant at the 0.05 level of significance. [LOS-Level of Significance; NA-Not Applicable]

while in group 2 it was observed in none of the newborns on day 2 and day 3. Statistically, these differences in duration of sleep of new born found to be associated significantly post administration on day $3(\mathrm{p}<0.02)$ with used techniques but no significant association before $(\mathrm{p}>0.05)$ administration at baseline and after administration on day $1(p>0.05)$ and day $2(p>0.05)$. However, these differences in duration of sleep of new born babies directed a better improvement in lactation among postnatal mothers of group 1 than group 2 .

Table 4 highlighted the score before and after administration of techniques in groups to measure the improvement in production of breast milk by assessing the holding, latching, audible swallowing, comfort (breast/nipple) and comfort level for baby behavior during feeding. Research showed that there was a successive and better improvement in both the groups at post administration on day 2 and day 3. Postnatal mothers of group 1 had noted with more improved lactation post administration on days 2 than mothers of group 2 . On day 3 post administration, $63.3 \%$ postnatal mothers of new born babies noticed with good category received back massage than $40.0 \%$ administered cumin seed laddo.

Total score among post natal mothers of group 1 found to be greater than group 2. Moreover, these scoring 


\begin{tabular}{|c|c|c|c|c|}
\hline \multirow[t]{3}{*}{ Parameter } & \multirow{3}{*}{$\begin{array}{c}\begin{array}{c}\text { Before Admin. } \\
\text { (Pre-test) }\end{array} \\
n(\%)\end{array}$} & \multicolumn{3}{|c|}{ After administration (Post-test) } \\
\hline & & Day 1 & Day 2 & Day 3 \\
\hline & & n (\%) & n (\%) & n (\%) \\
\hline \multicolumn{5}{|c|}{ Test scores and category (Group 1; Back massage) } \\
\hline 0.0-3.9 (Poor) & $13(43.3)$ & $11(36.7)$ & $1(3.3)$ & $0(0.0)$ \\
\hline 4.0-6.9 (Average) & $17(56.7)$ & $19(63.3)$ & $23(76.7)$ & $11(36.7)$ \\
\hline $7.0-10.0(\mathrm{Good})$ & $0(0.0)$ & $0(0.0)$ & $6(20.0)$ & $19(63.3)$ \\
\hline \multicolumn{5}{|c|}{ Test scores and category (Group 2; Cumin seed laddo) } \\
\hline 0.0-3.9 (Poor) & $11(36.7)$ & $8(26.7)$ & $0(0)$ & $0.0(0.0)$ \\
\hline 4.0-6.9 (Average) & $19(63.3)$ & $22(73.3)$ & $30(100.0)$ & $18(60.0)$ \\
\hline $7.0-10.0$ (Good) & $0(0.0)$ & $0(0.0)$ & $0(0.0)$ & $12(40.0)$ \\
\hline
\end{tabular}

differences projected that the therapy of back massage was more effective in improving lactation among postnatal mothers of newborn babies as compared to therapy of cumin seed laddo.

Comparison of parameters between postnatal mothers of group 1 and group 2 post administrations on day 1 is shown in Table 5. Mothers of group 1 found with little more improvements in lactation parameters were noted on day 1 than mothers of group 2. But all parameters were approximately same in both the groups at pre stage except number of nappies wetted. Mean number of nappies wetted in group 1 and group 2 at pre stage were 1.23 and 2.20 respectively which presented with a statistically strongly significant $(p<0.005)$ mean difference while increased on next day 1 but after administration the improvement found to be insignificant $(\mathrm{p}>0.05)$ on day 1 .

An insignificant ( $p>0.05)$ mean difference was noted for average frequency of stools in last 24 hours at pre stage and on day 1 between group 1 and group 2. Average pre feed mean weight of the baby between group 1 and group 2 at pre stage was not significantly $(\mathrm{p}>0.05)$ differed as compared to day 1 post administration. Average post feed weight of the baby between group 1 and group 2 at pre stage was not significantly $(\mathrm{p}>0.05)$ differed as compared to day 1 .

Little insignificant $(\mathrm{p}>0.05)$ mean difference in before feeding abdominal girth of the baby between group 1 and group 2 at pre stage and post administration on day 1 was noticed. The differences between group 1 and group 2 after feeding abdominal girth of the baby at pre stage and post administration on day 1 weren't significant $(\mathrm{p}>0.05)$. Lastly, the statistical agreement for the proposed research recorded a difference in mean total test scores between group 1 and group 2 at pre stage (3.86 and 4.06) and on day 1 (4.05 and 3.89) but the differences couldn't reach at statistical significance $(\mathrm{p}>0.05)$.

Table 6 shows the comparison between group 1 and group 2 post administrations on day 2 and day 3 . Mothers of group 1 noted with significant improvements on day 2 and day 3 post administrations in all lactation parameters when compared to mothers of group 2.

Mean number of nappies wetted group 1 and group 2 post administration on day 2 (6.00 and 3.97) were significantly $(\mathrm{p}<0.001)$ differed as compared to day 3 (9.10 and 5.97). Average frequency of stools in last 24 hours post administration on day 2 (3.87 and 3.20) between groups were statistically significant $(\mathrm{p}<0.05)$ while the differences were highly significant $(\mathrm{p}<0.002)$ on day 3 (5.67 and 4.47). Further, this was noticed that the mean differences of number of feed in last 24 hours post administration on day 2 (8.70 and 6.77) and on day 3 (11.17 and 8.30) between group 1 and group 2 was highly significant $(\mathrm{p}<0.001)$.

After administration, average pre feed mean weight of the baby on day 2 and day 3 between groups weren't statistical significant $(p>0.05)$. The present study documented a little difference in before feeding abdominal girth of the baby between group 1 and group 2 post administration at day 2 and day 3 but the differences were not statistically significant $(\mathrm{p}>0.05)$. The differences in after feeding abdominal girth of the baby post administration on day 2 and day 3 weren't significant $(p>0.05)$ between groups.

Mean time taken by the baby for breast feeding post administration on day 2 (8.66 and 6.46) and on day 3 (14.60 and 8.33) were significantly $(\mathrm{p}<0.001)$ differed between groups. Further, difference in mean total test score to judge holding, latching, audible swallowing, comfort (breast/nipple) and comfort level for baby behavior during feeding post administration on day 2 (5.51 and 5.03) was poorly significant but at the end of day 3 was statistically significant $(\mathrm{p}<0.05)$.

Moreover, the number of nappies wetted, frequency of stools and number of feed in last 24 hours, time taken by the baby for the breast feeding and total score were 


\begin{tabular}{|c|c|c|c|c|c|}
\hline \multirow{2}{*}{$\begin{array}{l}\text { Parameter } \\
\text { Between groups }\end{array}$} & \multicolumn{4}{|c|}{ Mean \pm Standard deviation } & \multirow[t]{2}{*}{ LOS } \\
\hline & Pre (E1) & Pre (E2) & Post Day 1 (E1) & Post Day 1 (E2) & \\
\hline \multicolumn{6}{|c|}{ Number of nappies wetted } \\
\hline E1 \& E2: Pre & $1.23 \pm 1.22$ & $2.20 \pm 1.35$ & - & - & $p<0.005^{\sharp}$ \\
\hline E1 \& E2: D1 & - & - & $3.27 \pm 1.48$ & $2.87 \pm 1.33$ & $p>0.05^{\otimes}$ \\
\hline \multicolumn{6}{|c|}{ Frequency of stools in 24 hours } \\
\hline E1 \& E2: Pre & $1.20 \pm 1.40$ & $1.63 \pm 1.13$ & - & - & $p>0.05^{\otimes}$ \\
\hline E1 \& E2: D1 & - & - & $2.00 \pm 0.87$ & $2.20 \pm 0.96$ & $p>0.05^{\otimes}$ \\
\hline \multicolumn{6}{|c|}{ Number of feed in last 24 hours } \\
\hline E1 \& E2: Pre & $5.83 \pm 1.29$ & $5.30 \pm 1.84$ & - & - & $p>0.05^{\otimes}$ \\
\hline E1 \& E2: D1 & - & - & $6.27 \pm 2.85$ & $5.97 \pm 1.16$ & $p>0.05^{\otimes}$ \\
\hline \multicolumn{6}{|c|}{ Pre feed mean weight of the baby (gram) } \\
\hline E1 \& E2: Pre & $2669.3 \pm 235.8$ & $2603.7 \pm 390.0$ & - & - & $p>0.05^{\otimes}$ \\
\hline $\mathrm{E} 1$ \& E2: D1 & - & - & $2643.8 \pm 272.2$ & $2582.1 \pm 389.2$ & $p>0.05^{\otimes}$ \\
\hline \multicolumn{6}{|c|}{ Post feed mean weight of the baby (gram) } \\
\hline E1 \& E2: Pre & $2652.8 \pm 272.7$ & $2607.1 \pm 391.3$ & - & - & $p>0.05^{\otimes}$ \\
\hline $\mathrm{E} 1$ \& E2: D1 & - & - & $2646.8 \pm 272.3$ & $2585.7 \pm 385.9$ & $p>0.05^{\otimes}$ \\
\hline \multicolumn{6}{|c|}{$\begin{array}{l}\text { Before feeding abdominal girth of the } \\
\text { baby (centimeter) }\end{array}$} \\
\hline E1 \& E2: Pre & $28.33 \pm 1.15$ & $28.03 \pm 1.54$ & - & - & $p>0.05^{\otimes}$ \\
\hline E1 \& E2: D1 & - & - & $28.40 \pm 1.19$ & $28.07 \pm 1.53$ & $p>0.05^{\otimes}$ \\
\hline \multicolumn{6}{|c|}{$\begin{array}{l}\text { Post feeding abdominal girth of the } \\
\text { baby (centimeter) }\end{array}$} \\
\hline E1 \& E2: Pre & $28.39 \pm 1.17$ & $28.08 \pm 1.57$ & - & - & $p>0.05^{\otimes}$ \\
\hline $\mathrm{E} 1$ \& E2: D1 & - & - & $28.27 \pm 1.95$ & $28.16 \pm 1.52$ & $p>0.05^{\otimes}$ \\
\hline \multicolumn{6}{|c|}{$\begin{array}{l}\text { Time taken by the baby for the breast } \\
\text { feeding (minute) }\end{array}$} \\
\hline E1 \& E2: Pre & $4.29 \pm 1.24$ & $4.00 \pm 1.50$ & - & - & $p>0.05^{\otimes}$ \\
\hline E1 \& E2: D1 & - & - & $5.37 \pm 1.37$ & $4.86 \pm 1.51$ & $p>0.05^{\otimes}$ \\
\hline \multicolumn{6}{|l|}{ Total score } \\
\hline E1 \& E2: Pre & $3.86 \pm 0.53$ & $4.06 \pm 0.83$ & - & - & $p>0.05^{\otimes}$ \\
\hline E1 \& E2: D1 & - & - & $4.05 \pm 0.77$ & $3.89 \pm 0.42$ & $p>0.05^{\otimes}$ \\
\hline
\end{tabular}

successively higher and improved on days 2 and 3 among postnatal mothers who received back massage of group 1 in comparison to postnatal mothers who received cumin seeds laddo of group 2 which clearly projected the effectiveness of the method of back massage.

\section{DISCUSSION}

Scientific research studies conducted during the last three decades have clearly proved that breastfeeding provides the most suitable nutrition for an infant. The present study offers an understanding of the identification of the therapy which is beneficial in improving lactation, technically, helpful in producing enough of breast milk among post natal mothers.

Study attempted to demonstrate the most compelling preventive modality of improving lactation among post natal mothers by making comparison between the efficacy of back massage and cumin seed laddoo techniques. The postnatal mothers in group 1 experienced the black appearance of stool of $100.0 \%$ new born on day 1 but on days 2 and 3 and found to be changed and had more frequently yellow in $96.7 \%$ babies. Appearance of stool of $100.0 \%$ new born babies of group 2 at posttest stage on day 1 was black but on days 2 and 3 was changed and noticed yellow in $70.0 \%$ babies. Appearance of stool found to be associated highly significantly post administration on day $2(\mathrm{p}<0.003)$ and day $3(\mathrm{p}<0.006)$ with used techniques. The results of present study is in approximate agreement with the study conducted by Nommsen-Rivers LA et al. in 2008, found that the stool passed by the babies were higher in experimental group. ${ }^{16}$

Various researches showed that back massage promotes the milk production in postnatal mother that increases the release of oxytocin from posterior pituitary which supports relaxation and bonding and may decrease anxiety and better enjoy breastfeeding ${ }^{17-19}$ On the upper back is an acupressure point and nerves that serve the breast originate in the upper spine, between the shoulder blades. Massaging this area relaxes the shoulders and promotes milk let-down. Cumin seeds being a galactagogues that help initiation, maintenance and 
Table 6: Comparison of lactation parameters between group 1 (E1) and GROUP 2 (E2) at pre and post administration on day 2 (D2) and day 3 (D3)

\begin{tabular}{|c|c|c|c|c|c|}
\hline \multirow{2}{*}{$\begin{array}{l}\text { Parameter } \\
\text { Between groups }\end{array}$} & \multicolumn{4}{|c|}{ Mean \pm Standard deviation } & \multirow[t]{2}{*}{ LOS } \\
\hline & Post Day 2 (E×1) & Post Day 2 (E×2) & Post Day 3 (E×1) & Post Day 3 (E×2) & \\
\hline \multicolumn{6}{|c|}{ Number of nappies wetted } \\
\hline E 1 \& E2: D2 & $6.00 \pm 1.53$ & $3.97 \pm 1.22$ & - & - & $\mathrm{p}<0.001^{\#}$ \\
\hline E 1 \& E2: D3 & - & - & $9.10 \pm 1.81$ & $5.97 \pm 1.52$ & $p<0.001^{\#}$ \\
\hline \multicolumn{6}{|c|}{ Frequency of stools in 24 hours } \\
\hline E $1 \&$ E2: D2 & $3.87 \pm 1.14$ & $3.20 \pm 1.24$ & - & - & $\mathrm{p}<0.05^{*}$ \\
\hline E $1 \&$ E2: D3 & - & - & $5.67 \pm 1.39$ & $4.47 \pm 1.53$ & $\mathrm{p}<0.002^{\#}$ \\
\hline \multicolumn{6}{|c|}{ Number of feed in last 24 hours } \\
\hline E 1 \& E2: D2 & $8.70 \pm 2.40$ & $6.77 \pm 2.25$ & - & - & $p<0.001^{\#}$ \\
\hline E $1 \&$ E2: D3 & - & - & $11.17 \pm 1.86$ & $8.30 \pm 1.90$ & $p<0.001^{\#}$ \\
\hline \multicolumn{6}{|c|}{$\begin{array}{l}\text { Pre feed mean weight of the } \\
\text { baby (gram) }\end{array}$} \\
\hline E $1 \&$ E2: D2 & $2626.0 \pm 273.8$ & $2563.7 \pm 382.1$ & - & - & $p>0.05^{\otimes}$ \\
\hline E $1 \&$ E2: D3 & - & - & $2588.1 \pm 266.8$ & $2556.0 \pm 377.4$ & $p>0.05^{\otimes}$ \\
\hline \multicolumn{6}{|c|}{$\begin{array}{l}\text { Post feed mean weight of the } \\
\text { baby (gram) }\end{array}$} \\
\hline E 1 \& E2: D2 & $2632.8 \pm 267.5$ & $2564.6 \pm 384.8$ & - & - & $p>0.05^{\otimes}$ \\
\hline E 1 \& E2: D3 & - & - & $2607.1 \pm 273.4$ & $2575.6 \pm 371.3$ & $\mathrm{p}>0.05^{\otimes}$ \\
\hline \multicolumn{6}{|c|}{$\begin{array}{l}\text { Before feeding abdominal girth of } \\
\text { the baby (centimeter) }\end{array}$} \\
\hline E $1 \&$ E2: D2 & $27.73 \pm 2.39$ & $27.84 \pm 2.08$ & - & - & $p>0.05^{\otimes}$ \\
\hline E $1 \&$ E2: D3 & - & - & $28.40 \pm 1.19$ & $28.07 \pm 1.53$ & $p>0.05^{\otimes}$ \\
\hline \multicolumn{6}{|c|}{$\begin{array}{l}\text { Post feeding abdominal girth of the } \\
\text { baby (centimeter) }\end{array}$} \\
\hline E $1 \&$ E2: D2 & $28.44 \pm 1.34$ & $28.01 \pm 2.06$ & - & - & $p>0.05^{\otimes}$ \\
\hline E 1 \& E2: D3 & - & - & $28.61 \pm 1.34$ & $28.11 \pm 1.96$ & $p>0.05^{\otimes}$ \\
\hline \multicolumn{6}{|c|}{$\begin{array}{l}\text { Time taken by the baby for the } \\
\text { breast feeding (minute) }\end{array}$} \\
\hline E $1 \&$ E2: D2 & $8.66 \pm 2.93$ & $6.46 \pm 1.56$ & - & - & $p<0.001^{\#}$ \\
\hline E 1 \& E2: D3 & - & - & $14.60 \pm 5.18$ & $8.83 \pm 1.64$ & $p<0.001 \#$ \\
\hline \multicolumn{6}{|l|}{ Total score } \\
\hline E 1 \& E2: D2 & $5.51 \pm 1.19$ & $5.03 \pm 0.75$ & - & - & $p<0.08^{\wedge}$ \\
\hline
\end{tabular}

augmentation of milk production act by increasing the production and release of prolactin by anterior pituitary by stimulating hypothalamus to secrete PRL (prolactin) releasing hormones ${ }^{20}$ in turn helps in the production of milk through prolactin reflex.

Post administration on day 3, 63.3\% postnatal mothers found with good category received back massage against $40.0 \%$ administered cumin seed laddo that showed the better efficacy of back massage in improving lactaion than cumin seed laddo. The difference in groups may be due of massage and during a study O'Connor et al. observed that massage is a relaxation technique, and reduces stress which probably is responsible for increase in milk output. ${ }^{21}$ Approximateky similar results was reported in a recent study carried out by Bhagyashree and Nilima (2016), observed that lactation improved significantly after back massage in experimental group this indicates back massage improved breast feeding scores significantly in experimental group than control group. ${ }^{22}$
Differences in mean time taken by the baby for breast feeding between groups on day 2 and on day 3 were significantly differed. Breast feeding is practiced by health care professionals for benefitting the mother and her child in all health aspects. Despite all its benefits certain mothers were unable to produce breast milk, which in turn affected the health of the child. ${ }^{8}$ There are certain beliefs and practices that do not encourage early initiation of breastfeeding. A study based on use of cumin seed powder as a catalyst for improvement in breast milk among postnatal mothers carried out by Subbiah and Jeganathan reported that almost 22.5 per cent of mothers said eating 'laddu' made up of cumin seed powder mixed with jaggery will increase the breast milk production. ${ }^{13}$

Study revealed that the back massage was more effective therapy for relaxing the mothers surely beneficial and helpful in production of more breast milk was correlated with respect to some parameters with present study 
conducted by Patel and Gedam. ${ }^{23}$ A study conducted in abroad by Tahir and Al-Sadat has been suggested that any form of postnatal lactation support will lead to an increase in exclusive breastfeeding rates. ${ }^{24}$ The important role of appropriate breastfeeding practices in the survival of infants is clear from this analysis. ${ }^{15}$

Overall, the research projected that the back massage had significant impaction on lactation among postnatal mothers of new born babies can improve the production of breast milk despite any other complications.

\section{Implications}

This study highlights the therapy which is beneficial in improving lactation, technically, helpful in producing enough of breast milk among post natal mothers. Back massage is a better effective technique advantageous to increase production of breast milk and decrease the risk of complication than cumin seed laddo and therefore awareness among nursing professional regarding the improvement in lactation among post natal mother of new born may create.

\section{CONCLUSION}

This study supports the view of improvement in lactation among post natal mother of new born by administering back massage which incorporated to significant health of new born. In the Indian context, there are many studies carried out on improvement in lactation among post natal mothers but none of the study demonstrated the comparison between lactation techniques. The findings of the study reported that back massage is better and is helpful in enough production of breast milk than cumin seeds laddo. The authors suggest that back massage among post natal mother of new born should become a "core component" when treating with low production of breast milk or health of new born in primary care.

\section{ACKNOWLEDGEMENTS}

Authors are grateful to Mrs Sushma Mercy Yohan, Sister Tutor and Ashish Noel Nand, Program Officer,JHPIEGO who helped in assessing the various parameters and provided valuable suggestions during research.

\section{REFERENCES}

1. Cunningham AS, Jelliffe DB and Jelliffe EFP. Breast-feeding and health in the 1980's; a global epidemiological review. J Pediatr 1991; 118: 659-666.

2. Blaymore JA, Oliver T, Ferguson A and Vohr BR. Human milk reduces outpatient upper respiratory symptoms in premature infants during their first year of life. J Perinatol 2002; 22:354-359.

3. Dewey KC, Heinig MJ and Nommsen-Rivers LA. Differences in morbidity between breast-fed and formula-fed infants. J Pediatr 1995; 126: 696-702.

4. Woodward A, Douglas RM, Graham NMH and Miles H. Acute respiratory illness in Adelaide children: breast-feeding modifies the effect of passive smoking. J Epidemiol Community Health 1990; 44: 224-230.

5. Wright AL, Holberg CJ, Martinez FD, Morgan WJ and Taussig LM. Breast-feeding and lower respiratory tract illness in the first year of life. Br Med J 1989; 200: 945-949.

6. WHO 2012. Essential Nutrition Actions: improving maternal, newborn, infant and young child health and nutrition. 1120. Available from: http://www.who.int/nutrition/publications/ infantfeeding/essential_nutrition_actions.pdf

7. Cowley KC. Psychogenic and pharmacologic induction of the let-down reflex can facilitate breastfeeding by tetraplegic women: a report of 3 cases. Arch Phys Med Rehabil 2005; 86(6):1261-1264.

8. Loganayagi K, Sumathi G and Nalini SJ. Effectiveness of reflex zone therapy among primi parae at selected hospital. Journal of Science 2014: 4(12) 732-735.

9. Dutta DC, Kona H. Text book of Obstetrics. Calcutta. JP Medical Ltd. 2014.

10. National Family Health. Survey (NFHS-3). 2005-06. Volume I. International Institute for Population Sciences. Deonar, Mumbai 400 088. Ministry of Health and family walfare. Available from: www.measuredhs.com/pubs/pdf/FRIN D3/FRIND3-VOL2.pdf

11. Wang HC, An JM, Han Y, Huang LN, Zhao JW, Wei LX, et al. [Multicentral randomized controlled studies on acupuncture at Shaoze (SI 1) for treatment of postpartum hypolactation]. Zhongguo Zhen Jiu 2007; 27(2):85-88.

12. United States Breastfeeding Committee, National Breastfeeding Center. Model Policy: Payer Coverage of Breastfeeding Support and Counseling Services, Pumps and Supplied. $2^{\text {nd }}$ revised edition Washington, DC: United States Breastfeeding Committee and National Breastfeeding Center; 2014.

13. Subbiah $\mathrm{N}$ and Jeganathan $\mathrm{A}$. socio-cultural beliefs influencing breastfeeding practices among primi postnatal mothers residing in urban slum area of Delhi. Health and Population -Perspectives and Issues 2012: 35(2) 61-73.

14. bushra F, Ahmad N, Hussain T and Manan F. Effect of feeding practices on birth interval and morbidity among children in North western frontier in Pakistan. Journal of Islamic Academy of Sciences 1995: 8(2) 69-72.

15. Arifeen S, Black RE, Antelman G, Baqui A, Caulfield L and Becker $S$. Exclusive breastfeeding reduces acute respiratory infection and diarrhea deaths among infants in Dhaka slums. Pediatrics 2001; 108(4):E67.

16. Nommsen-Rivers LA, Heinig MJ, Cohen RJ and Dewey KG. Newborn wet and soiled diaper counts and timing of onset of lactation as indicators of breastfeeding inadequacy. J Hum Lact 2008; 24(1):27-33.

17. Innis SM. Human milk: maternal dietary lipids and infant development. The Proceedings of the Nutrition Society 2007; 66(3):397-404.

18. Sheard $\mathrm{N}$. The role of breast milk in the development of the gastrointestinal tract. Nutrition Reviews 1988; 48(1):1-8.

19. WHO. Infant feeding: the physiological basis. Bulletin of the World Health Organization. 1989; 67(Suppl.):1-107.

20. Turkington RW: Molecular biological aspects of prolactin. In Wolstenholme GEW, Knight J (eds): Lactogenic Hormones, 
p 111. London: Churchill Livingstone, 1972

21. O'Connor ME, Schmidt W, Carroll-Pankhurst C and Olness KN Relaxation training and breast milk secretory IgA. Arch Pediatr Adolesc Med. 1998; 152(11):1065-1070.

22. Bhagyashree $A J$ and Bhore $N$. The effect of back massage on breast feeding among neonates who's mothers had undergone cesarean section. International Jour Sci Res 2016: 5(4)
2287-2290.

23. Patel $U$ and Gedam DS. Effect of back massage on lactation among postnatal mothers. Int J Med Res Rev 2013; 1(1):05-11.

24. Tahir NM and Al-Sadat N. Tahir. Does telephone lactation counseling improve breastfeeding practices?: A randomized controlled trial. Int. Jour. Nur Std 2013; 50(1) 16-25.

\section{Authors Contribution:}

AA- Concept and design of the study, reviewed the literature, manuscript preparation and critical revision of the manuscript; AV- Concept, collected data and review of literature and helped in preparing first draft of manuscript; BKS-Conceptualized study, literature search, statistically analysed and interpreted, prepared first draft of manuscript and critical revision of the manuscript; AKJ- Concept of study, collected data and review of study.

\section{Orcid ID:}

Anita Asrani: (1) http://orcid.org/0000-0002-0268-5985

Achamma Verghese: (iD http://orcid.org/0000-0002-1560-5075

Dr. Balkishan Sharma: (D) http://orcid.org/0000-0002-3517-0101

Source of Support: Nil, Conflict of Interest: None declared. 